\title{
Câmeras e espelhos em Big Brother Brasil: Enunciações e pragmática ${ }^{1}$
}

\author{
Dra. Suzana Kilpp \\ PPGCC - UNISINOS \\ sukilp@unisinos.br \\ Marcelo Bergamin Conter \\ BIC/PIBIC - UNISINOS \\ Álvaro Constantino Borges \\ UNIBIC - UNISINOS
}

\begin{abstract}
Resumo: $O$ presente artigo toma como objeto os construtos televisivos (ethicidades) de câmeras e espelhos presentes no programa Big Brother Brasil 3 (Rede Globo, 2002), e analisa tempos de TV em que os mesmos comparecem nos panoramas. O procedimento técnico básico é a dissecação de frames que, retirados do fluxo da tevê e digitalizados, evidenciam a produção e a edição das imagens, sendo que sua análise toma como base três enunciações principais do gênero reality show: vigilância, transparência e voyeurismo. Pretende-se problematizar essas enunciações em relação à pragmática da Rede Globo.
\end{abstract}

Palavras-chave: ethicidades televisivas; moldurações; pragmática.

\begin{abstract}
This article takes as study object the televised constructs (ethicities) of cameras and mirrors present in the Big Brother Brasil 3 show (Globo Network), and analyses the TV time these constructs appear in the panoramas. The basic technical procedure consists of dissecting the frames, which once withdrawn from the TV flow are digitalized, unveiling the images production and editing. The analysis is based on the three main enunciations of the reality show genre: surveillance, transparency and voyeurism. It aims problematizing these enunciations in terms of the Globo Network pragmatics.
\end{abstract}

$1 \mathrm{O}$ artigo decorre da pesquisa "A traição das imagens. Espelhos, câmeras e imagens especulares em reality shows", realizada na UNISINOS em 2005-2006, com apoio da FAPERGS e do CNPq. 
Key words: televised ethicities; framing; pragmatics.

Resumen: El siguiente artículo tiene como objeto las construcciones televisivas (ethicidades) de cámaras y espejos que se encuentran en el programa Big Brother Brasil 3 (Red Globo, 2002), y analiza tiempos de TV en que ellos aparecen en los panoramas. El procedimiento técnico básico es la disecación de frames que, retirados del flujo televisivo y digitalizados, evidencian la producción y la edición de las imágenes, siendo que su análisis toma como base tres enunciados principales del género reality show: vigilancia, transparencia y voyeurismo. El artículo pretende cuestionar esos enunciados en relación a la pragmática de la Red Globo.

Palabras-clave: ethicidades televisivas, molduraciones, pragmática.

\section{Câmeras e espelhos}

Atualmente as câmeras de vídeo estão em muitos e diversos lugares, já fazem parte até da paisagem urbana. Mas tal naturalização do olho eletrônico em nossas vidas se dá também por seu comparecimento em reality shows televisivos que é o que importa neste artigo -, sendo que, neles, sua presença, função e aplicação são diferentes e mais complexas do que em qualquer outro gênero televisivo. Assim também ocorre com espelhos - igualmente constitutivos da paisagem contemporânea -, que em nenhum outro panorama televisivo têm as características dos que comparecem em reality shows. Em todos os casos, porém, ambos - câmeras e espelhos - são, na TV, seres televisivos, construtos, ethicidades. 
O programa Big Brother Brasil 3 (Rede Globo, 2002) utiliza dezenas de câmeras e espelhos instalados e distribuídos em quase todos os espaços da reality house. As câmeras surgem aí, parece, com o papel de mostrar para o espectador o que ocorre dentro da casa, evidenciando a função escópica a elas atribuída expressamente pela produção do programa. Os espelhos, por sua vez, parecem inicialmente auxiliar a criação da identidade dos participantes, que flertam com suas imagens especulares, ajustando suas máscaras ao que lhes parece ser uma "boa imagem de si".

Em $B B B$, técnica e enunciativamente as câmeras são de dois tipos: câmeras visíveis, que são controladas eletronicamente e estão fisicamente presentes no cenário; e câmeras invisíveis, que são operadas manualmente e ficam por detrás de espelhos-janela. Quanto às visíveis, elas se encontram todas acima da altura dos participantes (e dos espelhos), como geralmente ficam as câmeras de vigilância, fazendo um contraponto aos espelhos que, por sua vez, naturalizam a forma como os participantes se relacionam dentro da casa. Quanto às invisíveis, elas ficam na altura dos olhos dos participantes, e sua disposição lembra as salas de interrogatório, onde os espelhos-janela garantem o anonimato do supervisor. Tanto as câmeras visíveis como as invisíveis são articuladas, realizando movimentos panorâmicos e efeito de zoom (as invisíveis, que ficam sobre trilhos, podem realizar também travelings pela casa).

Apesar de pertencer ao gênero reality show - ou talvez justamente por isso -, $B B B$ precisa esconder muito mais do que mostrar para parecer real. Enquanto espelhos e câmeras aparecem no panorama aumentando o realismo, em certos casos faz-se necessário justamente esconder a câmera que capta as imagens por trás de espelhos: este é o olhar escópico.

Quando se espia, nesse sentido, não basta não ser visto; devem ser também evitados outros indícios da presença do voyeur, como pegadas, ruídos, sombras e reflexos; ou então não há voyeurismo, mas outra coisa. Pode-se perceber esta enunciação no Frame 1, parte de um tempo de TV em que a imagem foi captada pela câmera invisível (o olho do voyeur) por trás de um espelho-janela. O espelho seria imperceptível se não houvesse no panorama uma fina linha esbranquiçada (indicada aqui pela elipse e seta) que percorre a imagem na vertical; ela é visível (em geral apenas pelo espectador mais atento) no contraste que faz com a camisa do 
participante, e é vestígio do encaixe de um espelho noutro. No Frame $2^{2}$ - que é um contra plano do Frame 1 - podemos ver outros encaixes de espelhos que compõem uma parede de espelhos por trás dos equipamentos da academia da casa.

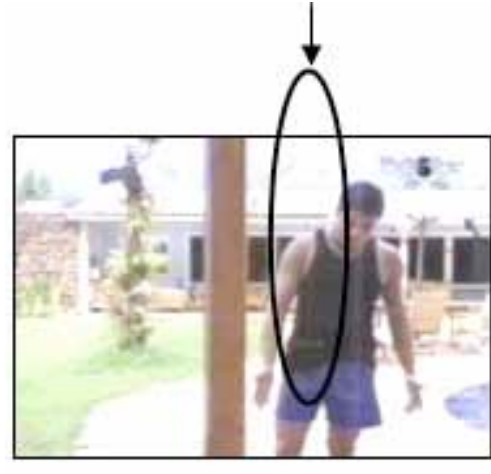

Frame 1

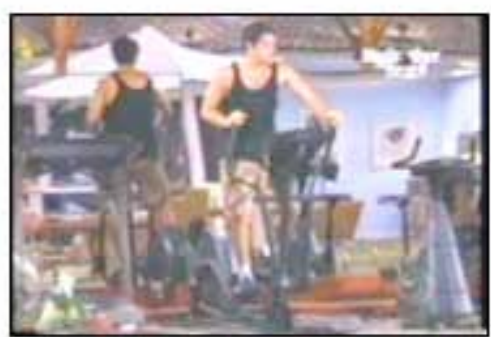

Frame 2

Como também se pode observar, logo atrás do participante (à esquerda) encontra-se uma câmera fixa instalada na ponta de um poste disfarçado com plantas. No frame pode-se notar a existência deste tipo de câmera, mas quando a imagem está no fluxo televisivo, tal elemento tende a passar despercebido. Será abordada adiante, no decorrer do texto, sua ethicidade3, além da de outros elementos que também tensionam as homologias de câmeras e espelhos.

Já foi tratada anteriormente a questão da angulação das câmeras visíveis, que ficam acima da altura dos espelhos e dos participantes, não só para reforçar a enunciação de vigilância, como também para evitar o comparecimento especular no panorama, tanto da própria câmera que capta quanto de outras. Como se faz necessário à lógica do programa a presença de câmeras à altura dos olhos dos participantes, os espelhos-janela surgem como um ponto de vista diferente, desta vez uma enunciação mais voyeurista que de vigilância, pois está claro para o espectador que assistiu a alguns programas que tal angulação corresponde a câmeras que são

2 Nele, observe também uma linha preta, agora horizontal, que atravessa o reflexo dos ombros do participante; a linha dobra para baixo em ângulo reto, ao centro da imagem, demarcando uma portinhola por onde a produção do programa introduz na casa o que é necessário à sua manutenção.

3 Subjetividades que a televisão dá a ver como tal, mas que são, na verdade, construtos televisivos, nas palavras de Kilpp (2003). 
"invisíveis" para os participantes da casa. Importante recorrer a Arlindo Machado (1987, p. 88-89), que em seu livro A ilusão epecular diz:

[...] na fotografia ocorre um sério problema: se faço desdobrar o espaço da cena colocando espelhos em campo, a própria câmera pode aparecer refletida nesses espelhos, comprometendo a inocência do efeito de "realidade". [...] A rigor, o fotógrafo e seus instrumentos técnicos constituem a única porção invisível da foto cuja presença não é um fetiche, pois é a condição da fotografia; mas a ficção do extraquadro a exclui de forma irremediável e lhe rouba o lugar.

A presença especular da câmera que capta as imagens no panorama desconstitui o olhar do espectador. Desde a Renascença, quando surge a concepção de perspectiva, convencionou-se que uma imagem, para ser realista, deve fazer com que o espectador sinta-se o criador da mirada: é preciso fazer com que ele não perceba que aquela imagem é criação do olhar de outrem. No momento em que um espelho inserido no panorama evidencia a câmera, revela-se o verdadeiro produtor da mirada, que não é o espectador, o que o faz se sentir excluído do processo. Por isso, na fotografia, ao registrar imagens especulares, e para aumentar o nível de realismo da foto, o fotógrafo também não deve aparecer especularmente, razão pela qual ele deve posicionar-se em um ângulo que mantenha seu corpo fora do alcance dos espelhos. Em $B B B$ não existe esta preocupação em relação às câmeras invisíveis, por elas estarem por detrás de espelhos-janela. Já as câmeras visíveis, estas não ficam na mesma angulação que os espelhos, e isto não é somente para reforçar sua ethicidade de câmeras de vigilância: é para que não sejam flagradas especularmente em imagens capturadas por elas mesmas, evitando assim um estranhamento da parte do espectador. Tal efeito pode ser observado, por exemplo, na obra $A$ arte da pintura (1665), de Jan Vermeer (Fig. 1, abaixo). Uma especular imagem especular sem nenhum espelho visível, onde o próprio pintor se inseriu na tela, de costas. 


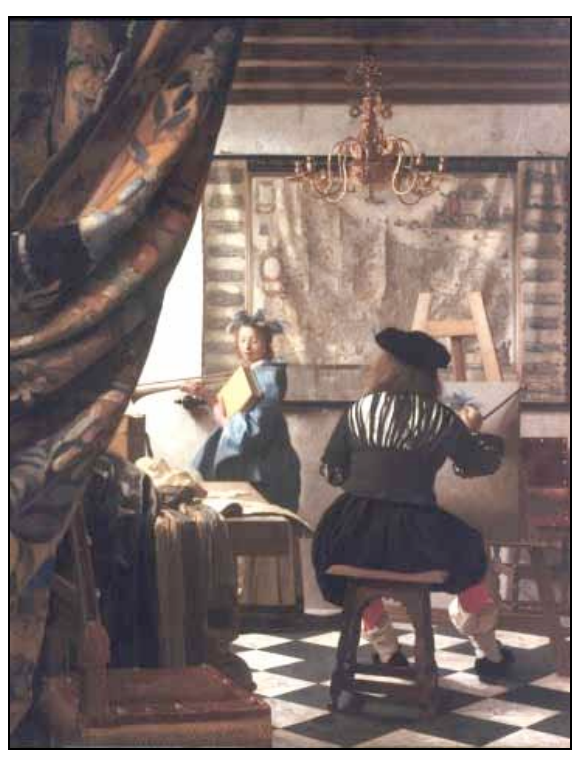

Figura 1

Já em $B B B$, os espelhos, além de servirem à produção da complexa especularidade a eles relacionada, eles permitem incluir no mesmo panorama imagens refletidas de outros ambientes da casa; assim, amplia-se a variedade de ângulos de cada tomada, colaborando para a dinâmica visual. Além disso, mostram/escondem (por serem, na verdade, espelhos-janela, vazados) as câmeras invisíveis, operadas manualmente. Por ser assim, os espelhos precisam esconder também os operadores de câmera, pois a presença de outras pessoas na casa mudaria todo o sistema de relacionamento entre os participantes; e precisam esconder ainda todos os bastidores da casa, que não interessam nem ao voyeurismo nem à vigilância.

Tanto as câmeras quanto os espelhos, quando presentes no panorama (o que acontece a maior parte do tempo) são, portanto, objetos que sujam a imagem, a ponto de contradizer a preciosa estética clean da Rede Globo de Televisão, seu padrão de qualidade técnica. Podemos pensar aí numa enunciação: Big Brother Brasil - mesmo que atravesse toda a programação da emissora, e mesmo que a casa cenário esteja situada dentro do PROJAC - não tem a mesma éthica ${ }^{4}$ dos mundos televisivos Globo. É um programa tão reality que só pode situar-se fora deles, no sujo mundo dos participantes e dos espectadores. Eis a transparência, o olhar objetivo da emissora sobre as relações sociais e as performances dos atores sociais.

4 O mesmo sentido identitário, a mesma ethicidade. 
A partir dessa breve introdução, nota-se que em Big Brother Brasil se cria uma nova ética de comparecimento de câmeras e espelhos no panorama televisivo. Esta ética evidencia o que entendemos como as três grandes enunciações dos reality shows: a vigilância, a transparência e o voyeurismo, que serão problematizadas em seguida.

\section{Vigilância}

En la época victoriana, el temor consistía en que el público pudiera lograr impertinente acceso a la vida privada de los miembros de la elite, como los políticos o los ricos. La realeza británica, entre otros, sigue luchando contra esto. Con la vigilancia electrónica, sin embargo, la ecuación se invierte. Ahora se piensa que son las vidas de los ciudadanos ordinarios las que están amenazadas por instituciones grandes y poderosas. (LYON, 1995, p. 31).

As câmeras visíveis, como mencionado anteriormente, ficam acima da altura dos espelhos para que seu reflexo seja evitado. Mas em alguns espaços da casa (e tempos de tevê), acabam comparecendo especularmente no panorama. É o caso do Frame 3, onde podemos ver (circulada) a discreta presença especular de uma câmera, que a princípio estaria fora-de-quadro. Esta câmera aparece novamente (também circulada) de forma especular no Frame 4, agora mais evidente.

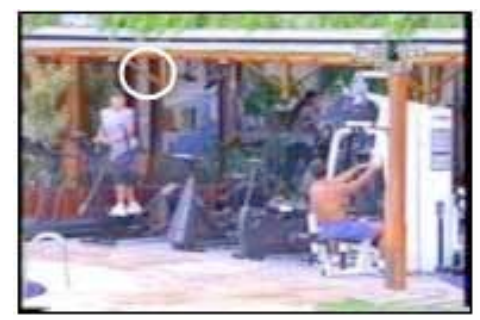

Frame 3

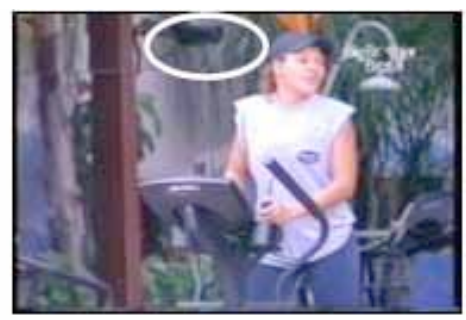

Frame 4

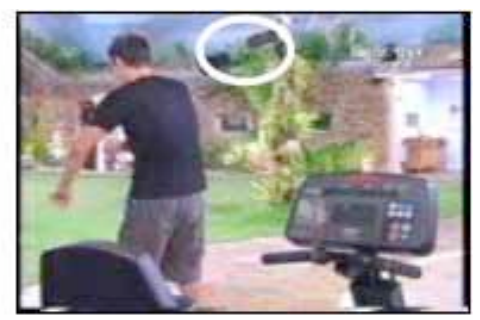

Frame 5

Estas imagens aparecem com freqüência nas seqüências tomadas na academia da casa, e por isso, ao longo de uma série de programas, elas vão se naturalizando. Embora os espelhos da casa possam ser considerados como molduras intrínsecas 5 , em vários momentos o ângulo de captura das câmeras se fecha de tal forma que não vemos as bordas do espelho (caso do Frame 4), o que faz com que a especularidade não seja percebida como tal. Mas não deixa de ser uma moldura.

5 Moldura designa aqui, nos termos de Kilpp (2003), as molduras e quase molduras que instauram, a partir de seus corpos, suas bordas ou manchas, territórios de significação. 
Mesmo que implícita, inclusive como moldura, há ainda a presença de pelo menos mais uma câmera nestas imagens, que é a que capta a imagem que vemos, e sua presença é justificada pela própria imagem: o comparecimento especular de uma câmera (Frames 3 e 4) traz para o panorama um determinado sentido, uma enunciação. Já no Frame 5 podemos ver a presença não-especular de uma câmera, uma sujeira de tipo diverso, mas também enunciativa.

Nos três casos são visíveis câmeras que estão direcionadas para um espaço outro, para um fora-de-quadro qualquer, como se fossem dispositivos de um olhar virtual. É como se fossem aparelhos de vigilância a serviço do espectador, lembrandoo que ele não deixará de ver nenhuma ação paralela, pois se algo interessante ocorrer fora-de-quadro, imediatamente lhe será mostrado. Então, a presença de câmeras visíveis (bem como a imagem especular delas) no panorama reforça dois aspectos da mesma questão: a enunciação da vigilância, e a do gênero de programa, que promete que tudo é visto, panopticamente.

Quanto aos espelhos, em sua pragmática inercial eles replicam e dão densidade dramática às imagens enunciativas, pois no lugar de uma parede optou-se por uma moldura intrínseca que, muitas vezes, também insere especularmente imagens que estão fora-de-quadro. Da mesma forma como as câmeras visíveis podem aparecer especularmente, elas podem se aproveitar dos espelhos para multiplicar os ângulos de uma mesma situação, concedendo aos participantes e aos espectadores um vasto e denso aparato virtual de vistas tecnicamente possíveis.

São, enunciativamente, inúmeras câmeras, espelhos, imagens especulares de câmeras e imagens especulares de imagens especulares que se montam nos panoramas, um excesso de imagens e de vistas que chega a ser inflacionário. Em $B B B$, assim como no Panóptico de Bentham, há mais "janelas" do que paredes, usadas aqui num sentido largo: molduras que nos dão a ver tudo, que nos permitem controlar tudo que acontece na casa.

Mas as considerações feitas ainda não são suficientes para comprovar a enunciação de vigilância. É preciso acrescentar que o sistema de vigilância do programa não tem como função essencial apenas a privacidade zero dos participantes com relação ao espectador; também tem a de permitir que a equipe de produção se 
assegure que os jogadores estão cumprindo as regras a eles impostas contratualmente, que são as primeiras regras de entrada e permanência na casa. É por isto também que há um caráter vigilante nas câmeras e espelhos: é a vigilância da Rede Globo sobre seu cast, que em geral passa desapercebida pelo espectador habituado.

Pode-se então distinguir duas formas de vigilância: uma, a serviço do espectador voyeur, e que podemos associar ao olhar escópico; e a outra, a serviço da produção do programa, que envolve cumprimento de contratos. É importante considerar a dimensão da vigilância sobre o voyeurismo televisivo nessas duas formas complementares, uma de caráter enunciativo e outra de caráter pragmático com vistas à promessa do gênero.

\subsection{Vigilância da produção}

Não se pode ignorar ou desmerecer a importância da vigilância da produção de $B B B$ para assegurar o conjunto de promessas que o gênero reality show faz ao espectador, até porque, como diz Lyon (1995, p. 91), "Se pierde de vista cuál es el desafío de la vigilancia electrónica si se reduce a una mera preocupación por la intimidad”, e há muito mais do que intimidade sendo prometida em $B B B$.

O cumprimento de várias regras contratadas entre emissora e participantes envolve o protagonismo das câmeras (e microfones) na delação (suspeita de crime) e no flagrante (prova). Por exemplo: é de responsabilidade dos participantes a limpeza da casa, da piscina e do jardim; também devem fazer sua própria comida e lavar sua roupa; eles têm obrigação de comparecer no Confessionário uma vez por dia, quando e onde conversam com um psicólogo e com a direção do programa sobre suas impressões sobre a estadia na casa; o concorrente que agredir outro participante ou quebrar algo na casa por livre e espontânea vontade será expulso do programa; etc. Como saber se os participantes estão fazendo isso sem utilizar-se de câmeras, já que não há contato físico algum entre eles e a produção enquanto estão na casa?

Para o espectador que assiste às imagens em fluxo e no interior de uma série de molduras e moldurações ${ }^{6}$ que só fazem intensificar sua sobreposição alucinada na

6 Procedimento de ordem técnica e estética que realiza certas montagens no interior das molduras. 
imagem síntese, com vistas a produzir efeitos de ação (muitas vezes inexistente no sentido de prender a atenção), muitos desses processos passam desapercebidos.

Quem vê imagem técnica parece ver seu significado, embora indiretamente. O caráter aparentemente não-simbólico, objetivo, das imagens técnicas faz com que seu observador as olhe como se fossem janelas, e não imagens. O observador confia nas imagens técnicas tanto quanto confia em seus próprios olhos. Quando critica as imagens técnicas (se é que as critica), não o faz enquanto imagens, mas enquanto visões do mundo. (FLUSSER, 2002, p. 13-14).

No cinema clássico, a justaposição de planos (montagem) buscou operar de forma a disfarçar a edição. Na tevê, especialmente nos reality shows, não só temos a contribuição da linguagem cinematográfica na junção de planos, como temos também as diversas molduras propriamente televisuais que vão complexificando os panoramas e envolvendo de mistérios sua produção. O espectador compreende as regras de permanência da casa, mas não faz idéia da forma como a edição e as molduras disfarçam a ação dos participantes em relação às regras da casa e produzem outros territórios de significação.

\section{Transparência}

Devido a que o conjunto dos fatos ocorridos na casa em seqüência e em paralelo tende a não ser interessante o suficiente para prender a atenção do espectador7, pois da ação coberta 24 horas/dia emergem poucos verdadeiros acontecimentos, a produção do programa realiza, com base nos mais variados subjects, as edições que vemos grande parte do tempo na TV aberta. O mais comum é uma espécie de resumo, para transmitir ao espectador aquilo que ela considerou que houve de mais relevante durante o dia (ou semana) dentro da casa. Também pode ser perfil dos participantes, coletânea de gafes, entre outros recortes temáticos.

Ocorre que, ainda que o espectador não veja tudo, os participantes são vigiados 24 horas, e é difícil para eles manterem sua máscara e performance todo o tempo. Aquele que, por exemplo, estiver tentando ser mais virtuoso do que realmente é, acaba, cedo ou tarde, sendo flagrado em contradição. Essa é uma das enunciações

7 Mesmo havendo edição - pois, por conta das inúmeras câmeras produzindo simultaneamente as imagens, é preciso decidir a todo o momento quais delas veicular -, nas transmissões full time pelo sistema pay per view da NET o programa é absolutamente enfadonho, monótono. 
da transparência televisiva, típica de reality shows como o Big Brother, flagrante éthico ${ }^{8}$ que a vigilância perscruta no conjunto das imagens gravadas. Nesse caso, a TV confronta para o espectador o autêntico éthico com o falso éthico ${ }^{9}$ e faz transparecer a ethicidade máscara (im) perfeita.

Como exemplo, há dois lugares na casa onde tal confronto é mostrado pela produção do programa com certa freqüência. O primeiro é de novo o Confessionário, no qual o participante fala com a produção ou com o psicólogo que a produção tem por assessor - ou com os espectadores, pedindo, por exemplo, para não ser eliminado. Seria a hora e o lugar em que o participante teria de ser (ou de parecer) mais autêntico. O segundo lugar da casa é o Gazebo. Ironicamente, este que é enunciativamente um dos locais mais públicos da casa, é ao mesmo tempo o mais privado para conversas pessoais. Isso é assim porque, como os participantes não podem trancar a porta de nenhum ambiente da casa ${ }^{10}$, aqueles que buscam privacidade (quanto aos outros participantes, pois não há como escapar das câmeras) a encontram ali, por poderem ver dali, de longe, a aproximação de qualquer outro participante sem serem surpreendidos. De novo, pode-se pensar como Lyon (1995, p. 257) que "Por tanto, los hogares se valoran especialmente por el refugio que ofrecen respecto a las demandas de la petición de explicaciones públicas”.

Se, por exemplo, determinado participante declara uma coisa no Confessionário que é contradita no Gazebo, a produção do programa pode facilmente juntar estes dois momentos particulares numa mesma edição e transmiti-los em seqüência, no fluxo que vai ao ar, dando transparência enunciativa a uma contradição que o espectador talvez nunca percebesse sem a pragmática vigilante da TV. O interessante é a duplicidade dessa pragmática: se por um lado, a edição desmascara os participantes do programa, por outro mascara a edição e a produção.

Nessa montagem, a TV mostra também, querendo ou não, como são construídas a seu modo as personas ${ }^{11}$ televisivas. Claro que são os participantes que

8 São sempre construtos televisivos.

9 Outra vez, como sentido identitário, como ethicidade, construto televisivo.

10 Só a produção do programa tem controle sobre as trancas das portas (eletronicamente), para fins de prover o necessário à manutenção da casa.

11 Personas são as pessoas que na TV interpretam personagens de si mesmos. São ethicidades (construtos televisivos) e também molduras, pois instauram territórios de experiência e significação às demais ethicidades que se constroem nos panoramas. 
constroem em primeiro lugar suas personas; mas deve-se sempre levar em conta que as moldurações realizadas pela produção - desde a escolha das imagens analíticas até a sua montagem e transmissão (imagem síntese) ${ }^{12}$ - são decisivas para os sentidos que serão agenciados ao final entre emissor e receptor.

\section{Voyeurismo}

Freqüentemente, nas transmissões do programa, bordas pretas integram os panoramas. Entendemos isto como uma sobra ou sujeira técnica que deseja estar ali para enunciar o voyeur, como um índice para o espectador: "veja o rastro, tem alguém espiando por você". As bordas pretas aparecem naqueles momentos em que os operadores de câmera por trás do espelho se vêem obrigados (ou não) a incluir no panorama a imagem do corredor por onde eles correm suas câmeras (como os dois frames abaixo demonstram).

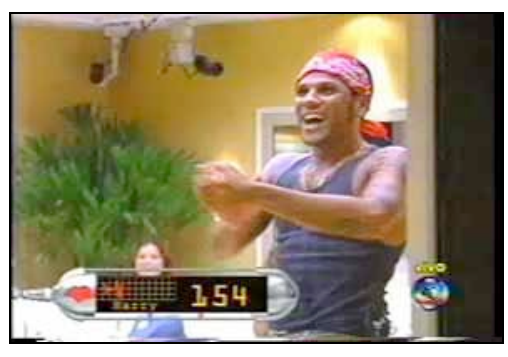

Frame 6

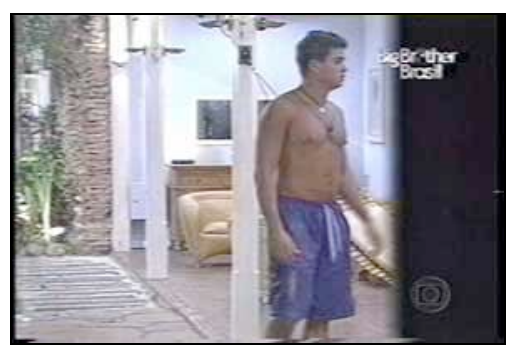

Frame 7

Quando essa escolha se faz necessária por causa, por exemplo, de movimentos rápidos do participante, difíceis de acompanhar, como no Frame 6, é admissível pensar em sujeira pragmática - fortuita, casual -, ainda mais quando a imagem vai ao ar ao vivo, sem pós-edição. Ao longo da história da instauração da linguagem televisual, muitos acidentes de percurso como esse foram se justificando através de consensos, da mesma forma como ocorreu com a instauração da linguagem cinematográfica. Na TV, a transmissão ao vivo sempre depende de muito improviso, sendo que "O espectador de televisão já se habilitou a um tipo peculiar de

12 Imagens analíticas são as tomadas que instauram o quadro e o fora de quadro em relação ao campo visual; sintéticas, são aquelas que vemos na tevê (conforme DERRIDA, 1998). 
construção em que controle e acaso convivem lado a lado no material simbólico [...]” (MACHADO, 2000, p. 134).

Já no Frame 7, que em tese não foi exibido ao vivo (pois não há logomarca na tela especificando), ao contrário da primeira, temos aqui uma imagem de movimento interno muito baixo, pois o corpo que a câmera segue caminha lentamente. Em outro gênero de programa da Rede Globo é bem provável que se preferisse cortar ou trocar esta imagem por uma capturada por outra câmera, a fim de limpar a imagem. Mesmo assim, manteve-se a presença dessa borda/moldura: o índice da câmera oculta, perceptível pela barra preta à direita no panorama, e que é relativa à angulação da câmera para além do espelho vazado. Nesse caso, estamos claramente diante do que Bellour chama de "forma-faixa".

Em seus estudos sobre cinema, Bellour teorizou sobre a "forma-faixa", que seria, como o nome diz, uma imagem em forma de faixa que corta outra imagem (o panorama), seja na horizontal ou na vertical. Tal construção imagética se realiza com freqüência no cinema, como num plano do filme Um corpo que cai (1958), de Alfred Hitchcock (Frame 8).

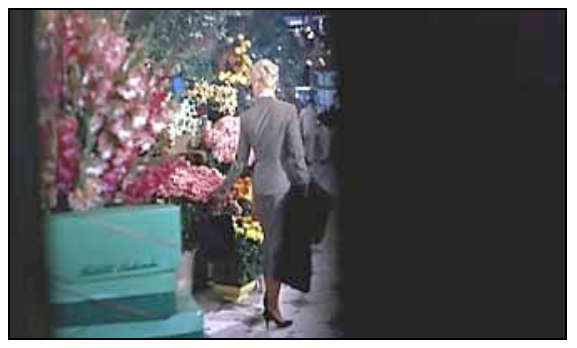

Frame 8

Segundo o autor, “A faixa [...] materializa a função do olhar, sua cesura, seus fora de campo, seu excesso e sua escassez. Ao variá-la, ele forma e formula a mesma e incansável questão: até que ponto se pode mostrar menos para ver mais?” (BELLOUR, 1997, p. 283).

Tudo indica que a forma-faixa no Big Brother opera da mesma forma que em Um corpo que cai, devido ao fato de que tanto o cinema quanto a TV desenvolverem sua linguagem através de consensos. A seqüência de frames a seguir, 
um traveling da direita para a esquerda produzida por uma câmera invisível por trás de um espelho-janela e editada antes de ir ao ar, aponta claramente para uma pragmática oportunista da Globo ao exibir as bordas negras. Esse movimento, que inscreve a forma-faixa como operador enunciativo, se dá claramente para intensificar o voyeurismo.
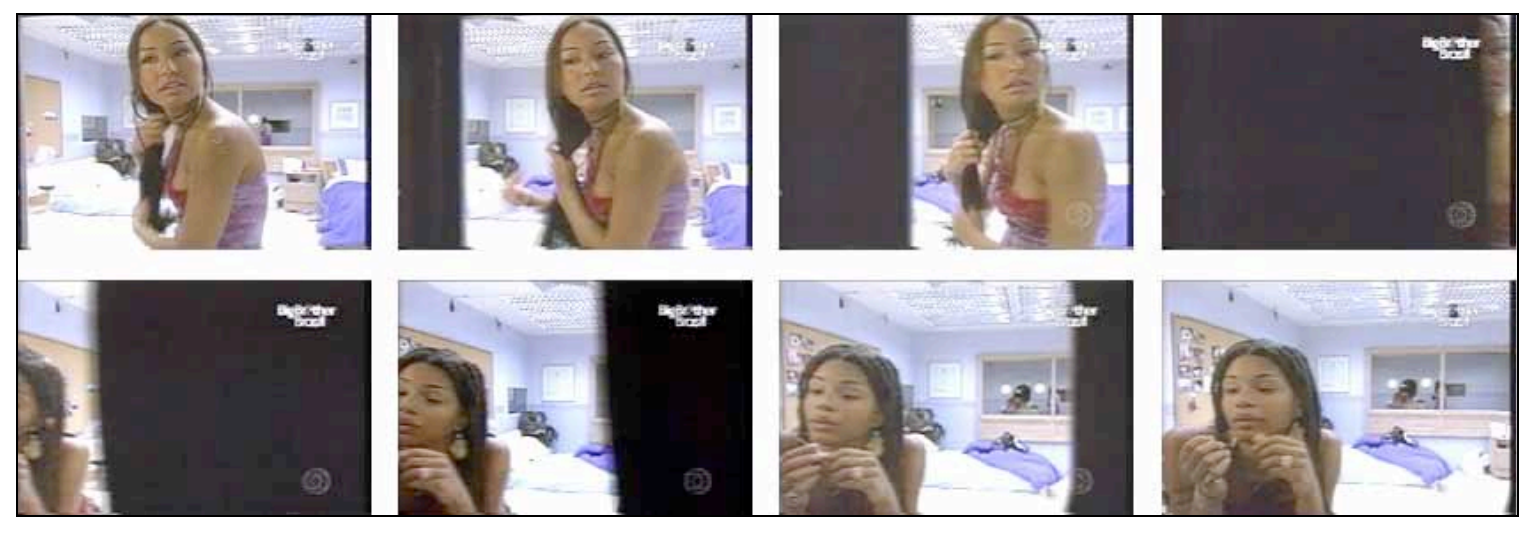

Seqüência 1

A forma-faixa, ainda segundo Bellour (1997, p. 279),

[...] induz efeitos de plano subjetivo entre os diversos fragmentos do quadro: em si mesma, pelo seu aspecto de fresta, de borda que o olhar pousa, ela escorrega para o fora de campo; mas também porque os motivos da imagem sempre supõem mais ou menos a presença ativa de um olhar. A forma-faixa chega a isolar o próprio olho. O olho voyeur e o olho visto.

Essas questões aparecem de outra forma nos Frames 9 e 10, onde se realizou um movimento de câmera (traveling) por trás de plantas. Pode-se perceber em uma construção de imagens como esta, bem como nas da forma-faixa, o modo como a Rede Globo autoriza e direciona o olhar do telespectador, passando a impressão de que ele é que é o voyeur que espia a intimidade dos participantes.

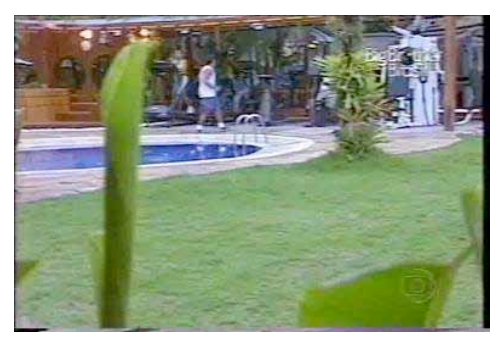

www.compos.com.br/e-compos

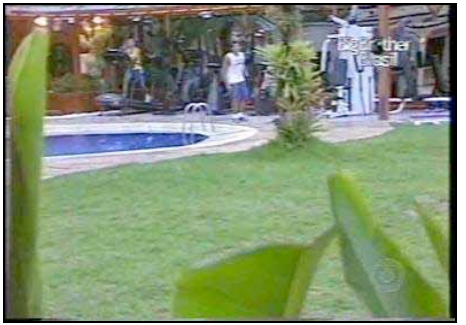

Abril de 2007 - 14/16 


\section{Frame $9 \quad$ Frame 10}

Como dito no começo do texto, à esquerda do Frame 1 há uma câmera na ponta de um poste disfarçado com plantas, sendo que a câmera se encontra no topo deste sem o disfarce. Pode-se pensá-la agora como olhos de um voyeur escondido por detrás da moita. E se conectarmos essa imagem com as dos Frames 9 e 10 percebe-se uma intenção enunciativa para a câmera, mesmo que as imagens destes dois últimos tenham sido captadas por outra câmera. Isso é assim porque se sabe que a apreensão espacial se dá através da sucessão de planos capturados em diferentes ângulos no fluxo televisivo (sua duração). Aí, há uma reiteração da imagem enunciativa, pois podemos ver de novo o poste do Frame 1 nos Frames 9 e 10, mais próximo da piscina.

Ou seja, em $B B B$ a Globo pratica reiteradamente duas formas-fórmulas de voyeurismo, o olhar pervertido que constrói ethicamente: esconde-se para mostrar (câmera por trás de espelho-janela), e se mostra escondida (forma-faixa). No caso dos frames 9 e 10 comparecem as duas formas.

Se, em momentos como este a Globo parece insinuar ao espectador que ele é o voyeur, como já foi visto é justamente aí que, ao contrário, aparece o voyeurismo da TV a serviço do espectador, o que é muito diferente: trata-se de um construto de voyeurismo expressamente televisual e televisivo, ao qual sujeita-se ou não o espectador.

\section{5 Éthica, enunciação e pragmática televisual}

Esperamos ter indicado, ainda que com a brevidade própria do artigo, que câmeras, espelhos e imagens especulares se articulam nos panoramas de $B B B$ à primeira vista em torno das três mais importantes enunciações afetas a esse tipo de reality show: vigilância, transparência e voyeurismo. Indicamos através de exemplos de panoramas (frames e seqüências) as articulações que remetem ora a uma, ora a outra enunciação ou a mais de uma. Mas também quisemos problematizar tais enunciações como sendo freqüentemente puro pragmatismo da Rede Globo, com vistas ao que o programa promete ao espectador e com vistas a necessidades operacionais da produção de $B B B$. 
Mais que isso, porém, intentamos demonstrar durante a análise que vigilância, transparência e voyeurismo em $B B B$ são construtos televisivos, são ethicidades cujos sentidos identitários são agenciados entre emissor e receptor a partir de um hábito metalingüístico, dos consensos historicamente estabelecidos na instauração da linguagem propriamente televisual.

E, a nosso ver o mais importante: quisemos reafirmar que em toda a parte, no fluxo televisual, a TV diz sempre, antes de tudo, de si mesma: no caso de $B B B$, é de seu voyeurismo, é de sua vigilância e de sua transparência que ela nos diz. Em $B B B$, a Rede Globo nos diz, mais do que em qualquer outro lugar de sua programação, quem ela é virtualmente e como ela age (se atualiza) em seu proclamado realismo asséptico, clean, acima de qualquer suspeita. Ora, pois.

\section{Referências}

BELLOUR, Raymond. Entre-imagens. Foto, cinema, vídeo. Campinas: Papirus, 1997.

DERRIDA, Jacques. Ecografias de la televisión. Entrevistas filmadas a Bernard Stiegler. Buenos Aires: Eudeba, 1998.

FLUSSER, Vilém. Filosofia da caixa preta. Rio de Janeiro: Relume Dumará, 2002.

KILPP, Suzana. Ethicidades televisivas. São Leopoldo: UNISINOS, 2003.

LYON, David. El ojo electrónico. El auge de la sociedad de la vigilancia. Madrid: Alianza Editorial, 1995.

MACHADO, Arlindo. A ilusão especular. São Paulo: Brasiliense, 1984. . A televisão levada a sério. São Paulo: SENAC, 200 